\title{
Polymer Nanocomposites and Applications: A Brief Review
}

\author{
S. K. Parida \\ Department of Physics, ITER, Siksha 'O' Anusandhan (Deemed to be University), Bhubaneswar-751030, India \\ *Corresponding Author: santoshparida@soa.ac.in
}

Available online at: www.isroset.org

Received: 21/Mar/2018, Revised: 29/Mar/2018, Accepted: 18/Apr/2018, Published: 30/Jun/2018

\begin{abstract}
It is a big challenge for material researchers to synthesis nanoparticles and nanocomposites with desire configurations in view of subtending all physical properties. Peoples from different fields show keen interest in making nanocomposites because of huge applications in all branches of science and technology. It was observed that nanocomposites are very useful for fabricating energy storage devices because of low ac conductivity, dielectric constant and high tangent loss. The novel nanocomposites can be used as biomaterials, self-cleansing materials and shape memory or smart materials.
\end{abstract}

Keywords: Polyurethane, Nanocomposites; Isophorene diisocyanate; Methyl ethyl ketone; biomaterials

\section{INTRODUCTION}

Synthesis of the nanoparticles and nanocomposites has been the subject of squinty in last few decades. The mechanical behavior of a material microstructure is the ultimate dream for material scientists. There is a paradox in materials science that the problem to be can be stated in so simple language but it is same degree of difficult to solve. Nanocomposites are mixing of different percentages of ceramics in which at least one of the phases must be in nano scale [1]. Nanocomposites materials are best available alternatives to overcome limitations of monolithic and micro-composites, even though there are lots of synthesis provocations associated with the reign of arrangement, type, and ratio of atoms in molecules of chemical substances and stoichiometry in the nanocluster phase. Nanocomposites are going to be the right alternative materials of $21^{\text {st }}$ century on account of having special design and enhance combined properties that are not equipped in other traditional composites. Till today we are far away from a general complete understanding of the mechanical behavior of nanocomposites [2-3]. It has been observed that below certain critical size of a particle, the changes in particle properties are taking place [4]. Additionally, when the particles dimension reduce to $\mathrm{nm}$ scale, then the interaction of the nanoparticles dominant at phase interfaces, which may be the reason for enhancement of different properties in materials. In these circumstances, the ratio of surface to volume of nanoparticles during preparation of nanocomposites is played a crucial role. So it is important to explore the structure-property relation of nanocomposites. Again a new flavour is added in this subject after the discovery of carbon nanotube (CNTs) in 1991 [5]. The CNTs has been studied extensively due to the some exciting results in electrical, mechanical and thermal properties [6-8]. The entry of CNTs into the composites and textiles [9] make the further expansion of the subject and its applications. At present environmental friendly nanocomposites [10] are syntheses, which propose advanced technology and business options for all sectors of industries.

On the basis of the structure of micro-composites, nanocomposite materials are divided into three distinct groups. (i) Ceramic Matrix Nanocomposites (CMNC) (ii) Metal Matrix Nanocomposites (MMNC) (iii) Polymer Matrix Nanocomposites (PMNC). In last decade, it has been observed that the conducting polymer-based composites are extensively studied due to some new novel properties over conventional composites [11], but it is a challenge for polymer scientists to control the behaviours of conducting polymers and optimized their different physical properties like electrical, thermal, optical and colloidal stability. People believed that even some lacuna are present in the handling conducting polymer, still hoping a great success will come to make commercial availability and give a big uplift to the materials science in forthcoming decade. The new progress in the different preparation techniques of biodegradable polymer-based nanocomposites have demand a wide branch of research. The current improvements in physical properties, structure, applications including crystallization behaviour of biodegradable polymer-based nanocomposites have been discussed [12-13]. Another interesting topic of research is the toughness and interfacial bonding between CNTs and polymer matrices [14]. A stress is generated due to intermixing of CNTs and polymer and transfer the stress from polymer matrix to CNTs which help 
for the production of macro scale CNT - polymer for huge applications in polymer industries. Just before the detail explanation of three different nanocomposites and their synthesis procedure, structure, physical properties and applications, let take few lines to describe the potential applications in different branches of science and technology. Normally ceramics have good wear resistance, high thermal and chemical stability but extremely brittle in nature. Due to very low toughness of ceramics, it has become a tripping to the wide applications in industry. To avoid the above limitation, people pay more attention towards ceramicmatrix nanocomposites having improved mechanical properties. The fracture toughness of the ceramic can be increased by adding suitable energy-dissipating materials such as fibres, platelets etc. [15-17]. Addition of energydissipating components produces more cracks inside the ceramic matrix and forced to change the phase transition in connection with volume expansion cause by the stress field, which may be the reason for enhancement of physical properties in nanocomposites [18].

A famous researcher Niihara [19-20] reported that $\mathrm{Al}_{2} \mathrm{O}_{3} / \mathrm{SiC}$ system is a ceramic matrix nanocomposite (CMNC). This result shows that $\mathrm{Al}_{2} \mathrm{O}_{3}$ ceramic matrix becomes comparatively harder after addition of very low around $10 \%$ volume fraction of $\mathrm{SiC}$ particles. Some other results suggest that the properties enhancement of the CMNC may be due to the role of crack-bridging mechanism [21]. Another way of trying to increase material properties is that addition of nanofibres into ceramic matrices. This method has a lot of difficulties with controlling the size, structure, properties and applications compared to previous case of $\mathrm{SiC}$ nanoparticles [22]. A special group of materials called as metal matrix nanocomposites (MMNC) refer to implantation of some nanosized metal in the ceramic matrix. Normally MMNC consists of both metal and ceramic characters so that metal nanocomposites are very hard having high degree of shear strength and thermal stability. Due to these properties MMNC members are the right choice for application in different branches of sciences and technology, such as aerospace, automotive industries and development of structural materials [23]. Polymer Matrix Nanocomposites (PMNC) may be the third category of the nanocomposites formed by introduction of polymer into the ceramic matrices. There are some challenges in controlling the structure and properties over other nanocomposites [24]. A new challenging research area comes up due to introduction of CNTs nanocomposites into the matrix of polymers like CMNC, MMNC and PMNC nanocomposites but after more than decade of rigorous research [25], CNTs did not comes up as a potential nanoscopic reinforcements [26-30] in polymer matrices. Thus mixture of CNTs with polymer nanocomposites still remains as one of exciting research topic for time to come.
In this paper, we discuss the different types of nanocomposites and their applications. In addition of the review the applications of nanocomposites, the synthesis of nickel based polymer nanocomposites have been discussed. The synthesis of nanostructure materials in chemical process normally offer some advantages over the physical methods in connection to simplicity, low cost, energy saving, short time of production and product homogeneity. Taking the above points in account, nickel-polyurethane nanocomposites were synthesized by chemical route. As nanocomposites have variety of applications in different branches of science and technology, we decide to prepare the nickel-polyurethane nanocomposites because of nickel based nanocomposites are extremely useful candidates related to electrical applications. As a whole, there are plenty of opportunities and rewards left in the field of nanocomposites, which attract many researchers from worldwide toward these materials.

\section{MeChanism}

There are many different methods to preparation polymer nanoparticles and nanocomposites. The novel polyurethane polymer nano-composites were fabricated keeping $\mathrm{NCO} / \mathrm{OH}$ ratio constant at $1 / 2$ with 5 weight percent of $\mathrm{Ni}$ nanoparticles by sol-gel method. First, the polyurethanes polymer is synthesized from the ethylene glycol and Isophorene diisocyanate (as monomers). The formation of polyurethane was ascertained by the FTIR spectrum. To prepare 5 weight $\%$ of nickel, $3 \mathrm{~g}$ of polyurethane was weighed and dissolved in a solvent methyl ethyl ketone (MEK) to make a solution and $0.15 \mathrm{~g}$ of highly pure nanosize nickel powder was added. Then the light yellow colour solution was formed and heated under vigorous stirring through a mechanical stirrer at $510 \mathrm{rpm}$ in $60^{\circ} \mathrm{C}$ temperature for 30 minutes for homogeneous mixing. The solution was slowly evaporated until a gel was formed. Then the product was poured into Teflon Petridis and then dried at room temperature for 24 hour. Before making pellets, again Petridis was kept in the oven at $70^{\circ} \mathrm{C}$ for 3 hours for avoiding air bubble. The require dimension of the sample pellets were prepared and put in a sample holder. 


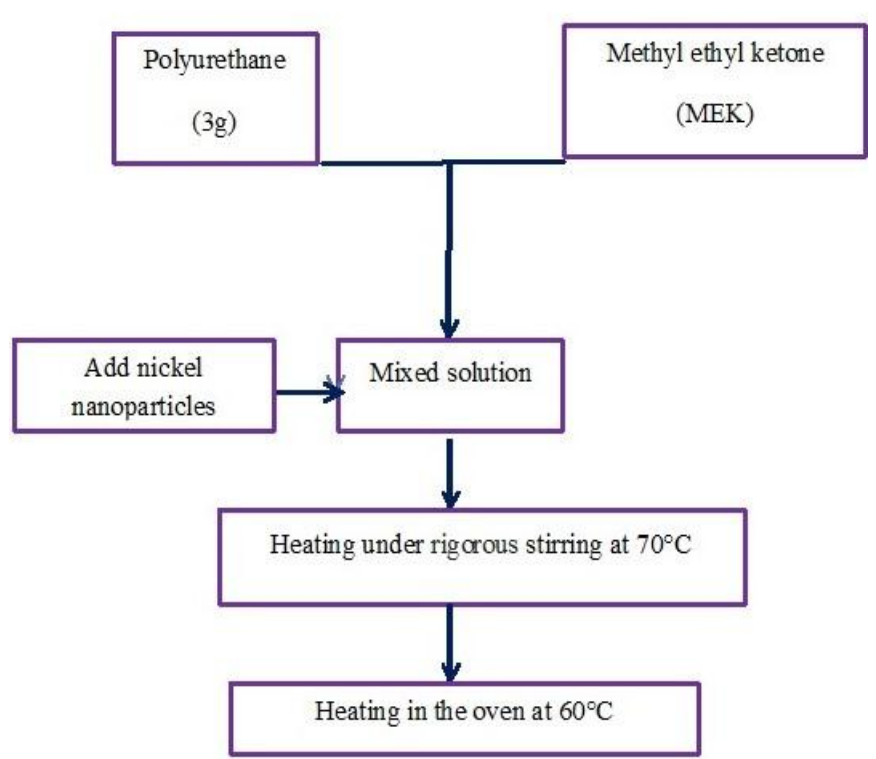

Fi.g1 Preparation technique of Nickel based polyurethane

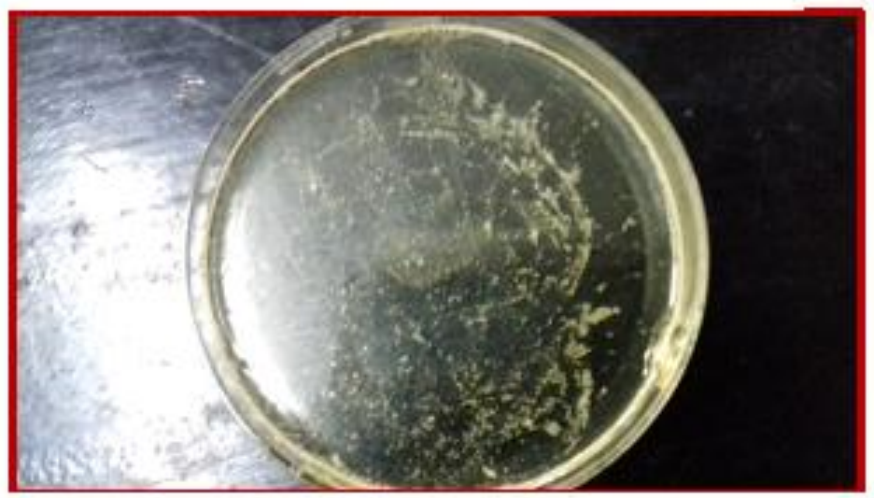

Fig.2 Nickel doped polyurethane $10 \mathrm{wt} \%$ samples

\section{CONCLUSION}

In conclusion, we discuss the different types of nanocomposites and their applications along with the detail synthesis technique of nickel-polyurethane nanocomposites. As nanocomposites have variety of applications in different branches of science and technology because of improved physical properties of composites. There are number of new technologies in which the performance of the composites can be improved compared to conventional available components. So, in this context nanocomposites are extremely good materials to meet the huge demands that coming from scientific and technologic advances. The preparation, application and challenges for different types of nanocomposites like CMNC, MMNC and PMNC have been discussed. It is clearly remark that the improved performance of the above nanocomposites is far better than monolithic and micro-composite counterparts and become first choice for material scientists over many existing materials and devices. Due to excellent improved physical properties of nanocomposites may require a new branch of science to study in future. In connection to the their special feature of nanocomposites such as high mechanical properties exist even at very low loading reinforcements, gas barrier and flame related properties make these materials separate from other and extremely useful in device fabrication and energy storage. At last, the existing all three types of nanocomposites provide wide opportunities and rewards to attract researchers from worldwide toward these new materials.

\section{ACKNOWLEDGMENT}

I am thankful to Department of Physics, ITER, Siksha 'O' Anusandhan (Deemed to be University), Bhubaneswar, for giving me support.

\section{REFERENCES}

[1]. R. Roy, R. A. Roy, D. M. Roy, "Alternative perspectives on "quasi-crystallinity": non-uniformity and nanocomposites", Materials Letters, vol. 4, pp. 323-328, 1986.

[2]. H. Gleiter, "Materials with ultrafine microstructures: retrospectives and perspectives", Nanostructured Materials, vol. 1, pp. 1-19, 1992.

[3]. R. K. Das, Applications of Metal Compound Nanomaterials in Quantum Dot Sensitized Solar Cells (QDSSC), International Journal of Scientific Research in Physics and Applied Sciences, Volume-5, Issue-5, pp.16-18, 2017

[4]. O. Kamigaito, "What can be improved by nanometer composites" Journal of Japan Society of Powder Metalurgy, vol. 38, pp. 315-321, 1991.

[5]. S. Iijima, "Helical microtubes of graphitic carbon", Nature, vol. 354, pp. 56-58, 1991.

[6]. M. J. Biercuk, M. C. Llaguno, H. J. Radosvljevicm, "Carbon nanotube composites for thermal management" Appied Physics Letters, vol. 80, pp. 2767-2769, 2002.

[7]. Z. Ounaies, C. Park, K. E. Wise, E. J. Siochi, J. S Harrison, "Electrical properties of single wall carbon nanotube reinforced polyimide composites", Composites Science and Technology, vol. 63, pp. 1637-1646, 2003.

[8]. M. C. Weisenberger, E. A. Grulke, D. Jacques, T. Ramtell, "Andrews R. Enhanced mechanical properties of polyacrylonitrile: multiwall carbon nanotube composite fibers", Journal of Nanoscience and Nanotechnology, vol. 3, pp. 535-539, 2003.

[9]. A. B. Dalton, S. Coolins, E. Muñoz, J. M. Razal, V. H. Ebron, J. P. Ferraris et al., "Super-tough carbon-nanotube fibres: these extraordinary composite fibres can be woven into electronic textiles", Nature, vol. 423, pp. 703-703, 2003.

[10]. Y. H. Choa, J. K. Yang, B. H. Kim, Y. K. Jeong, J. S. Lee, T. Nakayama et al, "Preparation and characterization of metal: ceramic nanoporous nanocomposite powders", Journal of Magnetism and Magnetic Materials, vol. 266, pp. 12-19, 2003.

[11]. R. Gangopadhyay, D. Amitabha, "Conducting polymer nanocomposites: a brief overview", Chemistry of Materials, vol. 12, pp. 608-622, 2000.

[12]. S. S. Ray, M. Bousmina, "Biodegradable polymers and their layered silicate nanocomposites: in greening the 21st century materials world", Progress in Matererials Science, vol. 50, pp. 962-1079, 2005. 
[13]. J. K. Pandey, A. P. Kumar, M. Misra, A. K. Mohanty, L.T. Drzal, R.P. Singh, "Recent advances in biodegradable nanocomposites", Journal of Nanoscience and Nanotechnology, vol. 5, pp. 497-526, 2005.

[14]. R. Andrews, M. C. Weisenberger, "Carbon nanotube polymer composites", Current Opinion in Solid State and Materials Science, vol. 8, pp. 31-37, 2004.

[15]. F. F. Lange, "Effect of microstructure on strength of si3n4-sic composite system", Journal of the American Ceramic Society, vol. 56, pp. 445-450, 1973.

[16]. P. F. Becher, "Microstructural design of toughened ceramics", Journal of the American Ceramic Society, vol. 74, pp. 255-269, 1991.

[17]. M. Harmer, H. M. Chan, G. A. Miller, "Unique opportunities for microstructural engineering with duplex and laminar ceramic composites", Ceramic Transactions, American Ceramic Society, vol. 22, pp. 617-619, 1991.

[18]. H. Awaji, S.M. Choi, E. Yagi, "Mechanisms of toughening and strengthening in cermaic-based nanocomposites", Mechanics of Materials, vol. 34, pp. 411-422, 2002.

[19]. K. Niihara, "New design concept of strctural ceramics-ceramic nanocomposites", Journal of the Ceramic Society of Japan, vol. 99, pp. 974-982, 1991

[20]. A. Nakahira, K. Niihara, "Strctural ceramics-ceramic nanocomposites by sintering method: roles of nano-size particles", Journal of the Ceramic Society of Japan, vol. 100, pp. 448-453, 1992.

[21]. L. P. Ferroni, G. Pezzotti, T. Isshiki, H. J. Kleebe, "Determination of amorphous interfacial phases in Al2O3/SiC nanocomposites by computer-aided high-resolution electron microscopy", Acta Materialia, vol. 49, pp. 2103-2113, 2001.

[22]. J. She, T. Inoue, M. Suzuki, S. Sodeoka, K. Ueno, "Mechanical properties and fracture behavior of fibrous $\mathrm{Al}_{2} \mathrm{O}_{3}$ /Sic ceramics", Journal of European Ceramic Society, vol. 20, pp. 1877-1881, 2000.

[23]. S. C. Tjong, G. S. Wang, "High-cycle fatigue properties of Albased composites reinforced with in situ TiB2 and Al2O3 particulates", Materials Science and Engineering: A, vol. 386, pp. 48-53, 2004.

[24]. SUVENDU PADHI, P GANGA RAJU ACHARY and NIMAI C NAYAK, "Molecular transport behaviour of organic solvents through halloysite nanotubes filled ethylene-vinyl acetate copolymer” Bull. Mater. Sci., Vol. 38, pp. 925-933, 2015.

[25]. R. Andrews, MC. Weisenberger, "Carbon nanotube polymer composites", Current Opinion in Solid State and Materials Science, vol. 8, pp. 31-37, 2004.

[26]. M. S. Dresselhaus, G. Dresslhaus, P. C. Eklund, "Science of fullerenes: carbon nanotubes", San Diego: Academic Press; pp. 1-870, 1996.

[27]. H. S. Nalwa, "Handbook of nanostructured materials and technology", New York: Academic Press, pp. 231-333, 2000.

[28]. M. S. Dresselhaus, G. Dresslhaus, P. Avouris, "Carbon nanotubes: synthesis, structure, properties and applications", Berlin: Springer Verlag; pp. 329-391, 2001.

[29]. P. M. Ajayan, L. Schadler, P. V Braun, "Nanocomposite science and technology", Weinheim: WILEY-VCH Verlag. GmbH \& Co. KGaA, Weinheim, pp. 1-223, 2003.

[30]. Alpha Gary, "Nanotubes of advanced polymer products", Plastics, Additives and Compounding, vol. 5, pp. 12$28,2003$.

\section{Author Profile}

Santosh Kumar Parida completed his PhD degree at Siksha 'O' Anusandhan University, Bhubaneswar, India. His teaching and research experience spans over more than one decades including B.Tech, M.Sc \& Ph.D. His studies involve synthesis of nano-particles and nanocomposites, alloys system and mathematical modelling and simulation. He has contributed

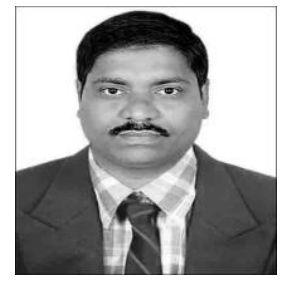

in many research papers in national/international journals of repute. 